\title{
A journal in ascendancy
}

Joint Editors-in-Chief

David Birch ${ }^{1}$, Yves Mely ${ }^{2}$ and Otto Wolfbeis ${ }^{3}$

1 Department of Physics (SUPA), University of Strathclyde, Glasgow G4 ONG, UK

2 UMR 7213 CNRS, Laboratorire de Biophotonique et Pharmacologie, Faculté de Pharmacie, F-67401 Illkirch, France

3 Institut für Analytische Chemie, Universitat Regensburg, 93040 Regensburg, Germany

E-mail: djs.birch@strath.ac.uk,yves.mely@unistra.fr and otto.wolfbeis@ur.de

Dear authors, reviewers and readers

We are delighted to report on another exciting and productive year for Methods and Applications in Fluorescence (MAF). Although only in its 3rd year the journal already seems to be living up to its promise of becoming the highest quality journal in the field.

For years many of the best fluorescence papers have been dispersed amongst more general journals, thus serving other areas rather than building up the reputation of fluorescence as a subject of importance in its own right. As editors in chief we firmly believe that fluorescence, as well as facilitating developments across the disciplines, should also gain wider recognition of its own worth which will benefit all of us in the fluorescence community.

This mission is very much at the heart of the new journal and we are pleased to report the growth of MAF in attracting high-quality work: doubling in size since its launch year in 2013. The quality of publications can be gauged by the average number of citations per article already being close to 3 . This is an outstanding index of quality for a new journal and one which has not gone unnoticed by others. During 2015 we received notice that Thomson Reuters' Web of Science and Elsevier's Scopus have both decided to include the journal in their citation reports. We await the announcement of the journal's first impact factor in 2016 with high expectation and a commitment to continue its rise.

Behind these metrics our authors have demonstrated the quality of their research through original research articles and reviews, special issues and video abstracts. Over the year the journal has published timely special issues on Super-Resolution Fluorescence Methods [1] edited by Alex Knight, Clemens Kaminski and Markus Sauer, Luminescent Imaging with Optical Chemical Sensors [2] edited by Michael Schaeferling and on Advanced Molecular Bioprobes [3] edited by Péter Kele which we feel will help to highlight some of the best work in these areas. Ever mindful of those new to the field or coming from different disciplines, we also publish review articles to bring readers a useful summary of the latest developments. The 16 reviews published to date have covered topics as diverse as the analysis of anisotropy decay data [4], intracellular probes [5, 6], luminescent lanthanide reporters [7], upconversion nanoparticles [8, 9] and the use of fluorescence to study biological membranes [10] and we are confident they will prove as popular and useful as the journal's first two reviews [11, 12], which have together been downloaded over 11000 times and have been cited well over 30 times to date.

As you will probably know the journal is closely linked to the internationally leading conference of the same name that gave rise to the journal. The $14^{\text {th }}$ biennial conference in the series held in Würzburg in September was yet another success with over 400 delegates attending. The keynote 
lecturers were Jennifer Lippincott-Schwartz and Joseph Lakowicz. We value the investment by IOP Publishing in being a Diamond Sponsor of the event and offer our warmest congratulations to organizer Markus Sauer and the whole local team that made the event such a great success. The special issue of MAF arising from papers presented at the meeting will be published in 2016. We are also planning for 2016 special issues on Fluorescence Research in the Ukraine and Excited State Proton Transfer studied by Fluorescence so please look out for these.

Finally all that remains is for us to express our thanks to all the authors, reviewers and editorial board who have supported the journal during the year by helping to maintain the high standards of research which the journal is committed to.

All good wishes for a happy and successful research New Year ahead.

David Birch, Yves Mely and Otto Wolfbeis

\section{References}

[1] Knight A, Kaminski C F and Sauer M 2015 Super-resolution fluorescent methods: where next for super-resolution? Methods Appl. Fluoresc. 3030201

[2] Schäferling M 2015 Luminescent imaging with optical chemical sensors Methods Appl. Fluoresc. 3 040202

[3] Kele P 2015 Advanced molecular (bio)probes-probes that are good, better, smarter Methods Appl. Fluoresc. 3040201

[4] Smith T A and Ghiggino K P 2015 A review of the analysis of complex time-resolved fluorescence anisotropy data Methods Appl. Fluoresc. 3022001

[5] Shi W, Li X and Ma H 2014 Fluorescent probes and nanoparticles for intracellular sensing of pH values Methods Appl. Fluoresc. 2042001

[6] Rowland C E, Brown C W III, Medintz I L and Delehanty J B 2015 Intracellular FRET-based probes: a review Methods Appl. Fluoresc. 3042006

[7] Vuojola J and Soukka T 2014 Luminescent lanthanide reporters: new concepts for use in bioanalytical applications Methods Appl. Fluoresc. 2012001

[8] González-Béjar M and Pérez-Prieto J 2015 Upconversion luminescent nanoparticles in physical sensing and in monitoring physical processes in biological samples Methods Appl. Fluoresc. 3042002

[9] Christ S and Schäferling M 2015 Chemical sensing and imaging based on photon upconverting nano- and microcrystals: a review Methods Appl. Fluoresc. 3034004

[10] Kyrychenko A 2015 Using fluorescence for studies of biological membranes: a review Methods Appl. Fluoresc. 3042003

[11] Demchenko A P 2013 Nanoparticles and nanocomposites for fluorescence sensing and imaging Methods Appl. Fluoresc. 1022001

[12] Demchenko A P and Dekaliuk M O 2013 Novel fluorescent carbonic nanomaterials for sensing and imaging Methods Appl. Fluoresc. 1042001 